\title{
KEANEKARAGAMAN JENIS LUMUT (BRYOPHYTA) DI DAERAH ALIRAN SUNGAI BEDADUNG JEMBER
}

\section{DIVERSITY OF MOSS SPECIES (BRYOPHYTA) IN THE BEDADUNG RIVER BASIN JEMBER}

\author{
Dwi Sucianingtyas Sukamto* \\ Universitas PGRI Argopuro Jember \\ *Email: dwisucianingtyas@gmail.com
}

\begin{abstract}
ABSTRAK
Keanekaragaman tumbuhan lumut (Bryophyta) di wilayah Jember khususnya di daerah aliran sungai Bedadung belum banyak dipelajari. Sungai Bedadung merupakan sungai terbesar di Kabupaten Jember yang melintasi ibu kota Kabupaten dengan panjang 46.875 meter. Tujuan dari penelitian ini adalah untuk menginventaris keanekaragaman jenis tumbuhan lumut di kawasan Daerah Aliran Sungai Bedadung sebagai upaya pemanfaatan lingkungan untuk sumber belajar mata kuliah perkembangan tumbuhan. Penelitian ini dilakukan selama 5 bulan yaitu dari bulan Januari 2015 sampai bulan Mei 2015. Metode pengoleksian tumbuhan lumut (Bryophyta) dilakukan dengan cara jelajah. Pengambilan sampel dengan menggunakan plot 2 × 2 meter dipasang di sepanjang jalur yang hanya ditemukan tumbuhan lumut. Identifikasi dilakukan dengan melihat karakter morfologi tumbuhan lumut. Hasil penelitian menunjukkan bahwa ditemukan 6 spesies yang tergolong dalam 3 Kelas tumbuhan lumut yaitu: Hepaticopsida, Anthocerotopsida dan Bryopsida. Spesies yang ditemukan adalah Anthoceros laevis, Lunularia cruciat, Riccia sp, Polytrichum commun, Dicranoweisia cirrata, Sphagnum sp.
\end{abstract}

Kata kunci: Bryophyta, Keanekaragaman, Lumut, Sungai Bedadung.

\begin{abstract}
The diversity of mosses (Bryiphyta) in Jember, especially in the Bedadung river basin, has not been studied much. Bedadung River is the largest river in Jember Regency which crosses the Regency capital with a length of 46,875 meters. The purpose of this study was to take an inventory of the diversity of moss species in the Bedadung River Basin area as an effort to utilize the environment for learning resources for plant development courses. This research was conducted for 5 months, from January 2015 to May 2015. The collection method of mosses (Bryophyta) was carried out by exploring. Sampling using a $2 \times 2$ meter plot was installed along the path where only mosses were found. Identification is done by looking at the morphological characters of mosses. The results showed that there were 6 species belonging to 3 classes of mosses, namely: Hepaticopsida, Anthocerotopsida and Bryopsida. The species found were Anthoceros laevis, Lunularia cruciat, Riccia sp, Polytrichum commun, Dicranoweisia cirrata, Sphagnum sp.
\end{abstract}

Keywords: Bryophyta, Diversity, Moss, Bedadung River. 


\section{PENDAHULUAN}

Indonesia merupakan salah satu negara yang memiliki keanekaragaman hayati terkaya. Diperkirakan 30\% tanaman dan 90\% hewan di Indonesia belum didata dengan lengkap dan didokumentasikan secara ilmiah. Salah satunya adalah tumbuhan lumut (Bryophyta) yang tumbuh liar di Indonesia. Tumbuhan lumut merupakan salah satu bagian flora sebagai penyokong keanekaragaman flora.

Lumut merupakan salah satu tumbuhan tingkat rendah yang hidup di lingkungan lembab. Habitat lumut secara umum terdapat pada batang pohon, kayu lapuk, batuan dan tanah. Tumbuhan lumut merupakan tumbuhan yang penting sebagai perintis di tanah-tanah yang gundul seperti lumut hati yang pada umumnya memainkan peranan kecil sebagai pengisi dalam vegetasi yang tinggi, lumut hati kadang sebagai pembantu dalam mengikat dan memantapkan permukaan tanah yang mengalami erosi (Polunin, 1990). Secara ekologis lumut berperan penting di dalam fungsi ekosistem. Seperti lahan gambut sangat tergantung pada lapisan atau tutupan lumut, sehingga keberadaan lumut sebagai penutup permukaan tanah juga mempengaruhi produktivitas, dekomposisi serta pertumbuhan komunitas di hutan (Hasan, 2004).

Materi Bryophyta pada mata kuliah Perkembangan Tumbuhan, meliputi ciri-ciri tumbuhan lumut, perkembangbiakan, klasifikasi dan contoh-contohnya. Pembelajaran tumbuhan lumut ini akan lebih baik jika mahasiswa tidak hanya mengetahui nama spesiesnya dan objeknya berupa ilustrasi atau gambar saja, tetapi mahasiswa dapat mengetahui secara langsung objek tumbuhan aslinya dengan memanfaatkan lingkungan sekitar kita sebagai sumber belajar (Kusuma, 2011).

Lingkungan di sekitar merupakan salah satu sumber belajar yang dapat dioptimalkan untuk pencapaian proses dan hasil pendidikan yang berkualitas bagi peserta didik. Memanfaatkan lingkungan sekitar dengan membawa anak-anak untuk mengamati lingkungan akan menambah keseimbangan dalam kegiatan belajar. Artinya belajar tidak hanya terjadi di ruangan kelas namun juga di luar ruangan kelas dalam hal ini lingkungan sebagai sumber belajar yang sangat berpengaruh terhadap perkembangan fisik, keterampilan sosial, dan budaya, perkembangan emosional serta intelektual.

Keanekaragaman tumbuhan lumut (Bryophyta) di wilayah Jember khususnya di daerah aliran sungai Bedadung, belum banyak dipelajari. Sungai Bedadung merupakan sungai terbesar di Kabupaten Jember. yang melintasi ibu kota Kabupaten dengan panjang 46.875 meter. Oleh karena itu, perlu dilakukan penelitian mengenai Keanekaragaman Jenis Lumut (Briophyta) di Daerah Aliran Sungai Bedadung Kabupaten Jember. 


\title{
METODE PENELITIAN
}

\section{Waktu dan Tempat Penelitian}

Penelitian ini dilakukan selama 5 bulan yaitu dari bulan Januari 2015 sampai bulan Mei 2015 yang meliputi pengambilan sampel dan pembuatan laporan. Penelitian dilakukan di Daerah Aliran Sungai Bedadung, Kecamatan Sukorambi, Kabupaten Jember.

\section{Keadaan Umum Lokasi Penelitian}

Secara geografis, daerah Jember terletak 83 meter dari permukaan air laut dengan lokasi koordinat 7 $59^{\prime} 6^{\prime \prime}-8^{\circ} 33^{\prime} 56^{\prime \prime}$ Lintang Selatan dan 6 $27^{\prime} 9^{\prime \prime}-7^{\circ} 14^{\prime} 33^{\prime \prime}$ Bujur Timur. Iklim di Kota Jember adalah iklim tropis. Angka temperatur berkisar antara $23^{\circ} \mathrm{C}-31^{\circ} \mathrm{C}$, dengan musim kemarau terjadi pada bulan Mei sampai bulan Agustus dan musim hujan terjadi pada bulan September sampai bulan Januari. Sedangkan curah hujan cukup banyak, yakni berkisar antara $1.969 \mathrm{~mm}$ sampai $3.394 \mathrm{~mm}$.

\begin{abstract}
Alat dan Bahan
Alat dan bahan yang digunakan dalam penelitian ini adalah alat tulis, kamera, tally sheet, termometer udara, higrometer, lux meter dan buku identifikasi Taksonomi Tumbuhan (Tjitrosoepomo, 2003), flora (Steenis, 2005) dan klasifikasi menggunakan buku Biology and Evolution of Ferns and Lycophytes (Ranker dan Haufler, 2008).

\section{Prosedur Penelitian}

Jenis penelitian pada penelitian ini adalah penelitian deskriptif kualitatif yaitu data hasil penelitian yang ditemukan di lapangan diinterpretasi dan dideskripsikan secara sistematis, faktual, dan akurat mengenai fakta dan sifat populasi tumbuhan.

Metode pengoleksian tumbuhan lumut (Bryophyta) dilakukan dengan cara jelajah, yaitu menjelajahi setiap sudut suatu lokasi yang dapat mewakili tipe - tipe ekosistem ataupun vegetasi di kawasan yang diteliti. Pengambilan sampel dengan menggunakan plot 2 × 2 meter dipasang di sepanjang jalur yang hanya ditemukan tumbuhan lumut. Sampel lumut yang ditemukan diukur basal areanya. Identifikasi dilakukan dengan melihat karakter morfologi tumbuhan lumut.
\end{abstract}




\section{HASIL DAN PEMBAHASAN}

Hasil pengamatan di DAS Bedadung kecamatan Sukorambi menunjukkan bahwa ditemukan 6 spesies yang tergolong dalam 3 Kelas tumbuhan lumut yaitu: Hepaticopsida, Anthocerotopsida dan Bryopsida. Spesies yang ditemukan adalah Anthoceros laevis, Lunularia cruciat, Riccia sp, Polytrichum commun, Sphagnum sp. Hasil pengamatan dapat dilihat pada Gambar 1.

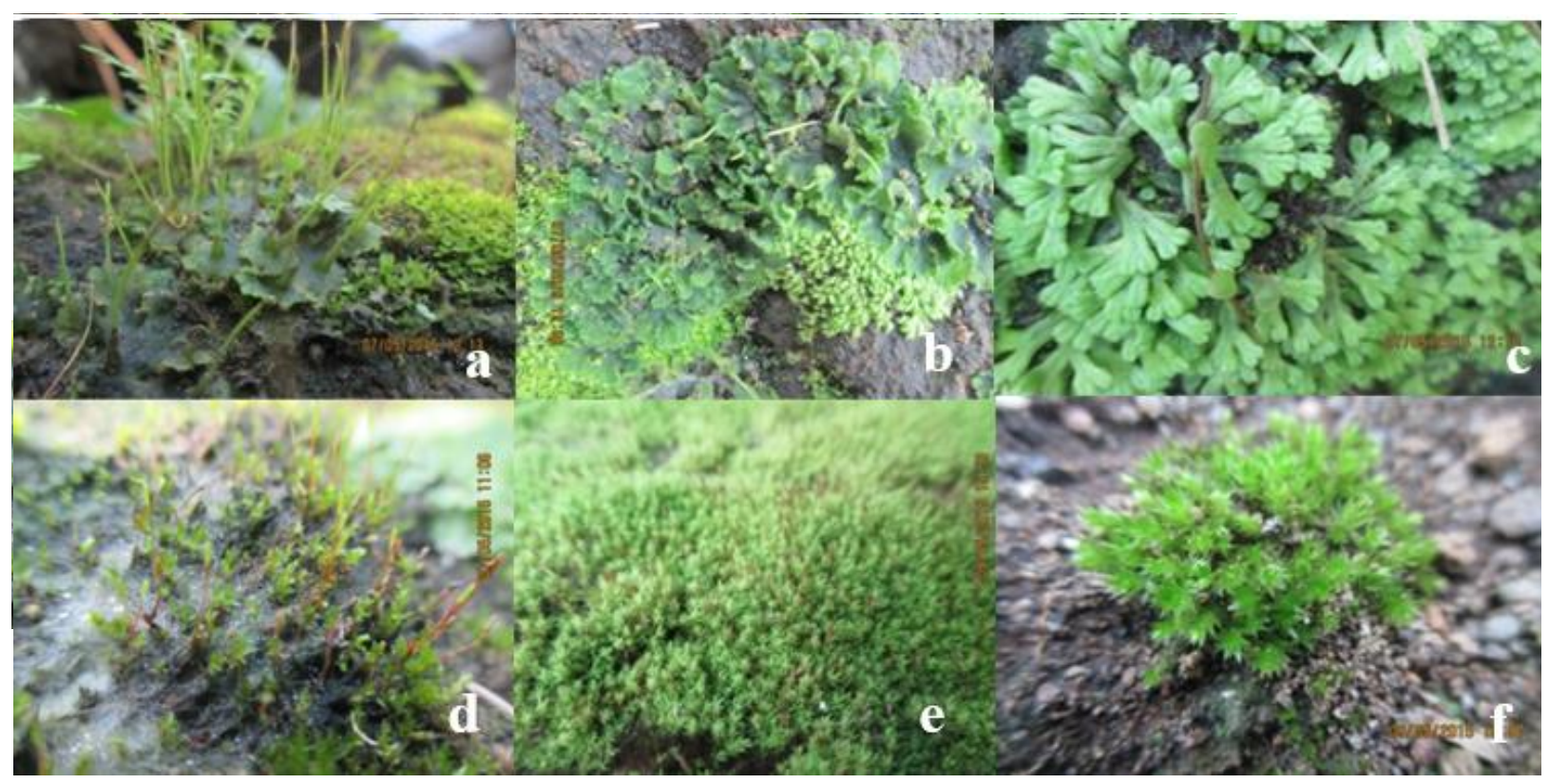

Gambar 1. Keanekaragaman jenis lumut di DAS Sungai bedadung Kabupaten Jember. Keterangan : a. Anthoceros laevis; b. Lunularia cruciat; c. Riccia sp; d. Polytrichum commun; e. Dicranoweisia cirrata; f. Sphagnum sp.

Berikut ini klafikasi dan beberapa sifat/ciri-ciri dari keanekaragaman jenis lumut di DAS sungai Bedadung kabupaten Jember:

\section{Anthoceros laevis}

Klasifikasi

Divisi : Anthocerotophyta

Kelas : Anthocerotopsida

Bangsa : Anthocerotales

Suku : Anthocerotaceae

Marga : Anthoceros

Jenis : Anthoceros leavis

Ciri Anthoceros leavis berdasarkan analisis asam nukleat, lumut ini berkerabatan paling 
dekat dengan tumbuhan berpembuluh (vaskuler) dibanding dari kelas lain pada tumbuhan lumut. Tubuhnya mirip lumut hati, tetapi berbeda pada sporofitnya. Sporofit pada lumut ini membentuk kampsul memanjang yang tumbuh seperti tanduk. Rhizoid berada pada bagian ventral. Gametofit berupa talus yang lebar dan tipis dengan tepi berlekuk. Habitatnya di daerah yang mempunyai kelembaban tinggi, contoh : Anthoceros leavis (Indriani, -).

\section{Lunularia cruciata}

\section{Klasifikasi}

Divisi : Hepatophyta

Kelas : Hepatopsida

Bangsa : Marchantiales

Suku : Lunulariaceae

Marga : Lunularia

Jenis : Lunularia cruciata

Ciri-cirinya adalah daunnya berbentuk lembaran-lembaran yang berkelok dibagian pinggirnya. Memiliki semacam akar yang tumbuh dari permukaan bawah tumbuhan hidup di tempat yang lembap.Warna kuning-hijau mengkilap. Bersifat tipis, pipih, yang merayap dan cenderung membentuk percabangan berulang kali yang sama besar. Permukaan talus pucat dan dihiasi dengan pori-pori dan pori-pori yang terikat oleh batas-batas bentuk pentagon (Prastyo, 2015).

\section{Riccia sp}

\section{Klasifikasi}

Kingdom : Plantae

Divisi : Bryophyta

Classis : Hepaticopsida

Ordo : Marchantiales

Famili : Marchantiaceae

Genus : Riccia

Spesies : Riccia $\mathrm{sp}$

Ciri-cirinya adalah kenampakan talusnya membulat, berbentuk seperti bintang menggarpu, mempunyai rusuk tengah yang tidak begitu menonjol, mempunyai rhizoid, tidak mempunyai gemma cup, jenis Riccia sp hampir sama dengan Marchantia hanya talusnya membulat. Kebanyakan hidup di darat atau tempat - tempat yang lembab (Windadari, 2009). 


\section{Polytrichum commune}

Klasifikasi

Regnum :Plantae

Division : :Bryophyta

Class :Polytrichopsida

Ordo :Polytrichales

Family :Polytrichaceae

Genus :Polytrichum

Spesies :Polytrichum commune

Ciri-cirinya hidup di tempat lembab dan sedikit basah. Tangkai tegak dan bercabangcabang. Bentuk sporangium bulat lonjong. Kaliptra adalah ujung spora yang menutupi sporangium. Kapsul adalah tangkai yang mendukung arkegonium dan antheridium. Filoid adalah bagian lumut yang menyerupai daun. Rhizoid adalah bagian dari lumut yang berfungsi menyerap zat-zat hara. Sporangium adalah kotak spora dan alat perkembang biakan.

\section{Dicranoweisia cirrata}

Klasifikasi

Regnum : Plantae

Division : Bryophyta

Kelas : Bryo psida

Ordo : Bryopceales

Family : Dicranaceae

Genus : Dicranoweisia

Spesies : : Dicranoweisia cirrata

Ciri - ciri : Hidup di tempat yang lembab atau basah, Mempunyai daun sederhana berbentuk pipih dan mengandung kloroplas. Berwarna hijau dan reproduksi generative.

\section{Sphagnum sp}

Klasifikasi

$\begin{array}{ll}\text { Regnum } & \text { : Plantae } \\ \text { Devisio } & : \text { Bryophyta } \\ \text { Classis } & \text { : Bryopsida } \\ \text { Ordo } & \text { : Sphagnales } \\ \text { Familia } & \text { : Sphagnaceae } \\ \text { Genus } & \text { : Sphagnum } \\ \text { Spesies } & \text { : Sphagnum sp }\end{array}$


Ciri-ciri Batangnya banyak bercabang-cabang, cabang yang muda tumbuh tegak,dan membentuk roset pada ujungnya. Daun-daun yang sudah tua terulai dan menjadi pembalut bagian bawah batang. Tidak memiliki seta. Sporangiumnya terletak langsung pada ujung filoid. Filoid adalah bagian lumut yang menyerupai daun. Rhizoid adalah bagian dari lumut yang berfungsi menyerap zat-zat hara.

Berdasarkan hasil penelitian tersebut diketahui bahwa tumbuhan lumut yang ditemukan sangat baik bila digunakan sebagai sumber belajar mata kuliah Perkembangan Tumbuhan pada pokok bahasan tumbuhan lumut (Bryophyta).

\section{SIMPULAN}

Hasil penelitian menunjukkan bahwa ditemukan 6 spesies yang tergolong dalam 3 kelas tumbuhan lumut yaitu: Hepaticopsida, Anthocerotopsida dan Bryopsida. Spesies yang ditemukan adalah Anthoceros laevis, Lunularia cruciat, Riccia sp, Polytrichum commun, Dicranoweisia cirrata, Sphagnum sp. Berdasarkan hasil penelitian tersebut diketahui bahwa tumbuhan lumut yang ditemukan sangat baik bila digunakan sebagai sumber belajar mata kuliah Perkembangan Tumbuhan pada pokok bahasan tumbuhan lumut (Bryophyta).

\section{DAFTAR PUSTAKA}

Hasan, M., Ariyanti, N.S. (2004). Mengenal Bryophyta (Lumut) di Taman Nasional Gunung Gede Pangrango Volume 1. Taman Nasional Gunung Gede Pangrango Cibodas.

Kusuma, U.G.A. (2011). Inventarisasi Tumbuhan Lumut (Bryophyta) di Kawasan Wisata Air Terjun Tirto Kemanten, Kecamatan Kalibaru, Kabupaten Banyuwangi sebagai Sumber Belajar Biologi. Skripsi. Pendidikan Biologi. FKIP. Universitas Jember.

Polunin, N. (1990). Pengantar Geografi Tumbuhan dan Beberapa Ilmu Serumpun. Gajah Mada: University Press.

Prastyo, W. R., Heddy, S., Nugroho, A. (2015). Identifikasi Tumbuhan Paku Epifit pada Batang Tanaman Kelapa Sawit (Elaeis guineensis J.) di Lingkungan Universitas Brawijaya. Jurnal Produksi Tanaman, 3 (1), 65-74.

Ranker, TA, dan Haufler, CH. (2008). Biology and Evolution of Ferns and Lycophytes, Cambridge University Press, New York.

Tjitrosoepomo, G. (2003). Taksonomi Tumbuhan. GajahMada University Press. Yogyakarta.

Windadari, F. I. (2009). Keragaman Lumut pada Marga Pandanus di Taman Nasional Ujung Kulon, Banten. Jurnal Natur Indonesia, 11. (2 ), 89-93. 